\title{
Editorial Note: Forensics of Multimedia Covert Communication
}

Multimedia Tools and Applications gratefully acknowledges the editorial work of the scholars listed below on the special issue entitled, "Forensics of Multimedia Covert Communication."

Of 80 papers submitted to this issue, 39 were eventually accepted after a stringent peer-review process.

Prof. Xiangyang Luo

State Key Laboratory of Mathematical Engineering and Advanced Computing Zhengzhou Science and Technology Institute, China xiangyangluo@126.com

\section{Prof. Yun-Qing Shi}

New Jersey Institute of Technology, USA

shi@njit.edu

\section{Prof. Jinwei Wang}

Nanjing University of Information Science \& Technology, China wjwei@nuist.edu.cn

\section{Prof. Qi Liu}

Edinburgh Napier University, UK

q.liu@napier.ac.uk

\section{Prof. Dengpan Ye}

Wuhan University, China

yedp@whu.edu.cn

Publisher's Note Springer Nature remains neutral with regard to jurisdictional claims in published maps and institutional affiliations. 